\title{
Copper-catalyzed enantioselective 1,2-borylation of 1,3-dienes $\uparrow$
}

Cite this: Chem. Sci., 2018, 9, 5284

\begin{abstract}
Yangbin Liu, Daniele Fiorito and Clément Mazet (DD *
A highly enantioselective $\mathrm{Cu}$-catalyzed borylation of 2-substituted 1,3-dienes is reported. The use of a chiral phosphanamine ligand is essential in achieving high chemo-, regio-, diastereo- and enantioselectivity. It provides access to a variety of homoallylic boronates in consistently high yield and enantiomeric excess with 2-aryl and 2-heteroaryl 1,3-dienes as well as sterically demanding 2-alkyl 1,3-dienes. Preliminary investigations based on a non-linear effect study point to a mechanism involving more than one metal center.
\end{abstract}

Received 4th April 2018

Accepted 22nd May 2018

DOI: $10.1039 / \mathrm{c} 8 \mathrm{sc} 01538 \mathrm{~d}$

rsc.li/chemical-science

highlighted by the fact that up to 6 different isomers can be

\section{Introduction}

Conjugated 1,3-dienes represent a particularly attractive platform for selective functionalizations. They do occur in some natural products and have often been used as bifunctional building blocks for the synthesis of biologically active molecules as well as in several polymerization processes. ${ }^{1,2}$ From a selectivity standpoint, functionalization of 1,3-dienes represents a significant challenge due to the numerous coordination and insertion modes conceivable for a transition metal catalyst. $^{3}$ To date, efforts to develop selective catalytic transformations have been essentially focused on linear 1,3-dienes (i.e. 4-substituted 1,3-dienes). ${ }^{4}$ Until recently, the limited synthetic accessibility of 2-substituted 1,3-dienes has hampered their use in the development of selective transformations. ${ }^{5}$ Moreover, most examples were focused on isoprene and myrcene, two readily available substrates of this subclass of conjugated dienes. Consequently, the effect of electronic and steric modifications has not been systematically investigated. For instance, the introduction of an aryl instead of an alkyl substituent at position 2- of a conjugated diene is likely to impart substantial changes in substrate polarity and/or in steric demand (Fig. 1A). Our laboratory recently reported a general procedure which streamlines access to 2-substituted 1,3-dienes and we decided to initiate a program on the selective functionalization of this underexplored scaffold. ${ }^{6}$

Among the approaches to functionalize 1,3-dienes, transition metal-catalyzed hydroborations and borylations have emerged as attractive strategies providing access to polyfunctionalized - potentially enantioenriched - structural motifs. For 2 -substituted substrates, the selectivity challenge is

University of Geneva, Department of Organic Chemistry, 30 quai Ernest Ansermet, 1211 Geneva-4, Switzerland. E-mail: clement.mazet@unige.ch

$\dagger$ Electronic supplementary information (ESI) available: Experimental procedures, characterization of all new compounds and spectral data. See DOI: $10.1039 / \mathrm{c} 8 \mathrm{sc} 01538 \mathrm{~d}$ generated upon exclusive mono-functionalization (Fig. 1B). Allylic boronates resulting from formal 1,4- or 4,1-hydroborations of 2-substituted 1,3-dienes have been reported by the groups of Suzuki and Ritter using highly chemo-, regio- and stereoselective Pd, Rh and Fe catalysts. ${ }^{7}$ Homoallylic boronates obtained by a 4,3-selective hydroboration are less common. Ito,

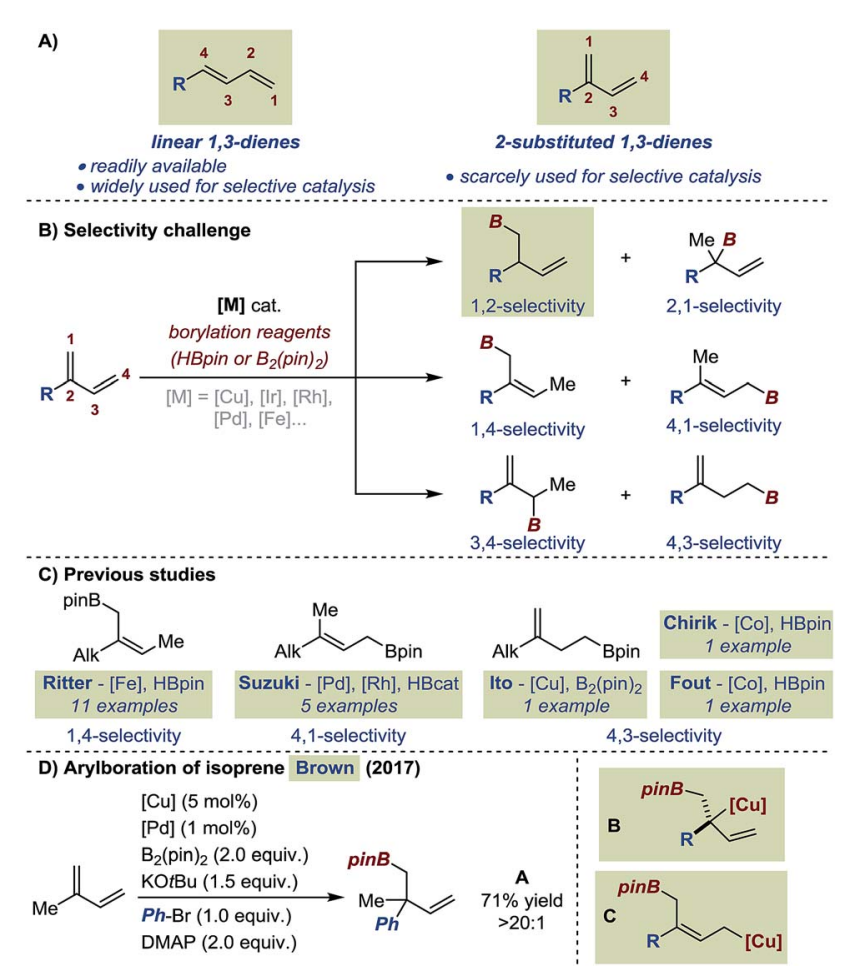

Fig. 1 (A) Linear vs. 2-substituted conjugated 1,3-dienes. (B) Selectivity challenges in hydroboration and borylation of 2-substituted 1,3dienes. (C) Previous hydroborations/borylations of 2-substituted 1,3dienes. (D) Arylboration of isoprene along with putative primary and tertiary $\mathrm{Cu} \sigma$-allyl intermediates. 
Fout and Chirik only described such products in studies where the focus was initially set on the hydroboration of cyclic 1,3dienes and terminal alkenes. ${ }^{8}$ To our knowledge, methods to access products of 1,2-, 2,1- and 3,4-selective hydroboration are absent from the current literature (Fig. 1B). Cu/Pd-catalyzed cooperative carboboration of alkenes represents another emerging class of transformation which involves the transient generation of copper-alkyl intermediates prior to transmetalation to a palladium catalyst. ${ }^{9}$ In this context, only few reports have placed emphasis on 1,3-dienes. ${ }^{10}$ The Brown group recently disclosed the highly selective arylboration of isoprene and myrcene unexpectedly leading to the exclusive formation of A when 4-dimethylaminopyridine (DMAP) was employed as additive (Fig. 1D). ${ }^{10 a}$ Interestingly, to account for this unusual selectivity preliminary mechanistic investigations do not support the formation of a congested $\mathrm{Cu}-\sigma$-allyl intermediate such as B (Fig. 1D) but rather transmetalation to Pd from a putative 1,4-borocupration species such as C. Within this context, at the outset of our investigations, we aimed at establishing a perfectly 1,2-selective borylation of 2-substituted 1,3dienes to access valuable enantioenriched homoallylic boronates. ${ }^{11}$ Herein, we describe the successful realization of our objective with the development of a highly chemo-, regio-, and enantioselective Cu-catalyzed borylation of a variety of 2substituted 1,3-dienes.

\section{Results and discussion}

Our study commenced by evaluating several chiral ligands for the Cu-catalyzed borylation of $1 \mathrm{a}$ using prototypical reaction conditions favoring borylcupration $\left(\mathrm{B}_{2}(\mathrm{pin})_{2} / \mathrm{MeOH}\right.$; Table 1). ${ }^{12,13}$ With ligands L1-3, homoallylic boronate $\mathbf{3 a}$ was obtained predominantly along with trace amount of the desired 1,2-borylated product $2 \mathrm{a}$ (conv. $=67-86 \%$; Entry 1-3). The commercially available bisphosphine $(R)$-BDPP afforded $2 \mathrm{a}$ and 3a in a nearly $1: 1$ ratio with a low but measurable enantioselectivity for the former (2a: $24 \% e e$, Entry 4). Using either diastereoisomers of the well-established phosphoramidite ligands L5 and L6, 2a was obtained as major regioisomer albeit in mixture with both 3a and $(E)$-4a (a product of formal 1,4-borylation) and in low ee (Entry 5-6). The chiral heterotopic ligand $(R)$-Quinap $\mathbf{L 7}$, enabled to increase both the relative ratio in favor of 2a as well as its enantiomeric excess (2a: $43 \% e e$; Entry 7). A slightly improved result was achieved with Simplephos L8 a structure introduced by the Alexakis group which rapidly established itself as a ubiquitous ligand in numerous $\mathrm{Cu}$-catalyzed enantioselective transformations. ${ }^{14}$ Given the higher modularity of $\mathbf{L 8}$ compared to $\mathbf{L} \mathbf{7}$, several members of the Simplephos family were evaluated next (See ESI $\uparrow$ for details) and allowed for identification of $\mathbf{L} \mathbf{9}$ as the best congener for the borylation of $\mathbf{1 a}$ (Entry 9). Further optimization of the solvent, temperature, concentration, time and copper source led to a system which afforded homoallylic boronate $2 \mathbf{a}$ as a single regioisomer $(2 \mathbf{a}: 3 \mathbf{a}>20: 1)$ in $82 \%$ yield and $90 \%$ ee (Entry $10-15$ ).

The scope of the process was first evaluated for 2-(hetero) aryl substituted 1,3-dienes. In most cases only products resulting from 1,2- and 4,3-borylation were detected. The selectivity was
Table 1 Reaction optimization ${ }^{a}$

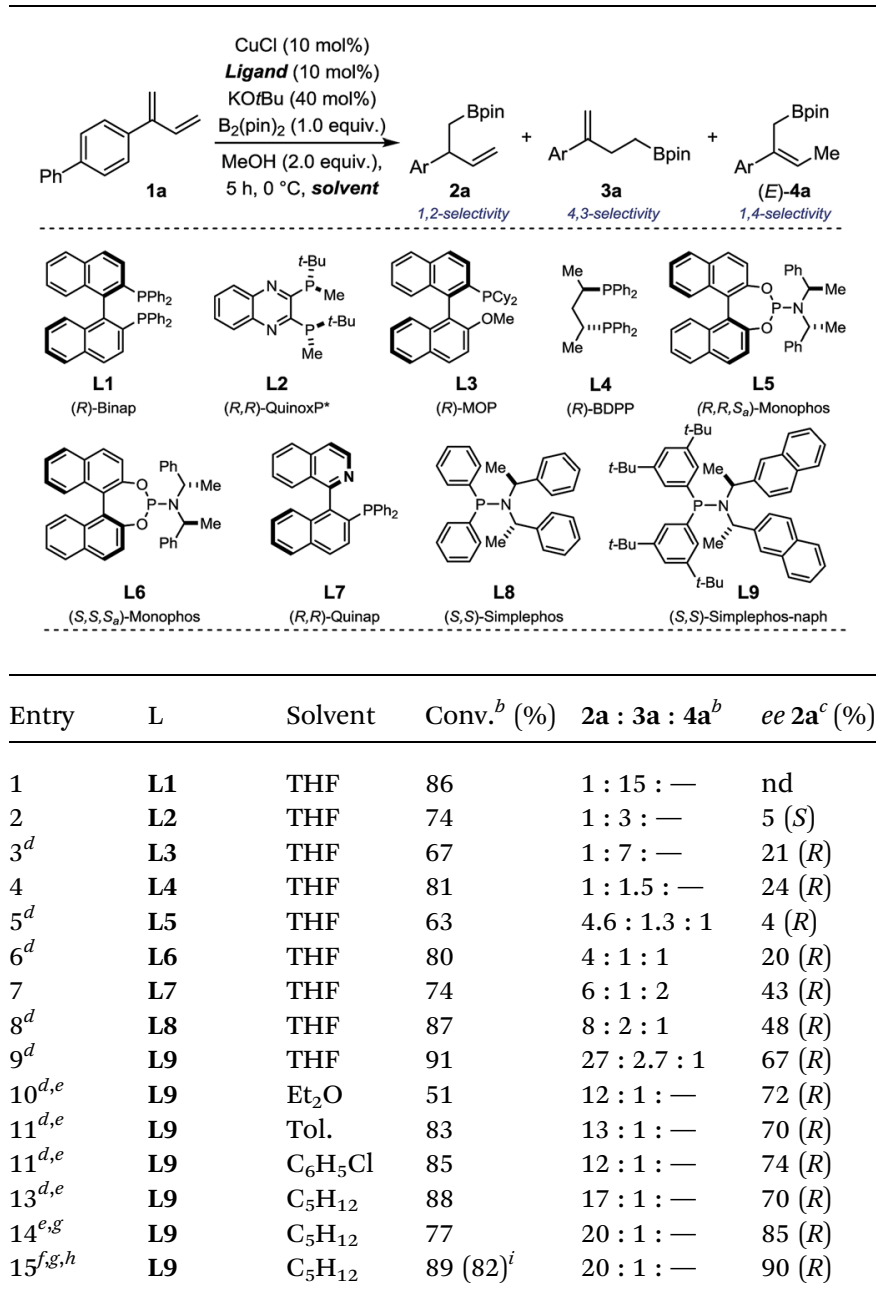

${ }^{a}$ Reaction conditions: $1 \mathrm{a}(0.12 \mathrm{mmol}), \mathrm{B}_{2}(\text { pin })_{2}(0.10 \mathrm{mmol}), 0.3 \mathrm{M}$. ${ }^{b}$ Determined by ${ }^{1} \mathrm{H}$ NMR using an internal standard. ${ }^{c}$ Determined by HPLC using a chiral stationary phase after oxidation to the corresponding alcohol $2^{\prime}$ a. ${ }^{d} 20 \mathrm{~mol} \%$ of ligand. ${ }^{e} 0.1 \mathrm{M} .{ }^{f} 0.15 \mathrm{M}$. ${ }^{g}-40{ }^{\circ} \mathrm{C}, 40 \mathrm{~h} .{ }^{h} \mathrm{CuO} t \mathrm{Bu}(10 \mathrm{~mol} \%)$, without base. ${ }^{i}$ Yield over 2 steps after oxidation to $2^{\prime} \mathbf{a}$ and purification by column chromatography.

assessed by analysis of the crude reaction mixture after borylation and the yields and enantiomeric excess were measured after oxidation into the corresponding homoallylic alcohols (20 examples, Fig. 2). Overall, most conjugated 1,3-dienes containing electron-rich, electron-neutral and electron-deficient aromatic substituents participated well in the $\mathrm{Cu}$-catalyzed borylation reaction, delivering the product in moderate to good yield, good to excellent regioselectivity and high enantioselectivity (2'a-2'1: $56-82 \%$ yield; chemoselectivity: $2.6: 1$ to > $20: 1 ; 86-91 \% e e$ ). Several functional groups (methoxy, fluoro, amino, trifluoromethyl, chloro) are tolerated. Whereas a homoallylic alcohol having a $p$-CN substituent $\left(\mathbf{2}^{\prime} \mathbf{n}\right)$ was isolated in much reduced yield albeit in high $e e, \mathbf{2}^{\prime} \mathbf{o}$ which displayed an alkyne substituent was generated in high yield, chemo- and enantioselectivity. Reduced performances were observed in the borylation of heteroaromatic-containing 1,3-dienes although satisfactory enantioinduction were still measured for $\mathbf{2}^{\prime} \mathbf{p}$ and 

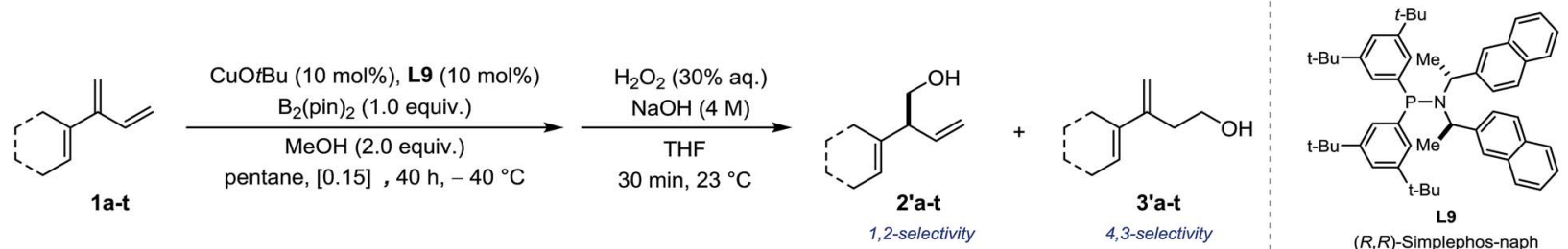<smiles>C=CC(CO)c1ccc(N(C)C)cc1</smiles>

2'a: $82 \%$ yield $>20: 1 ; 90 \%$ ee<smiles>C=CC(CO)c1ccc(Cl)cc1</smiles>

2'h: $80 \%$ yield $>20: 1 ; 89 \%$ ee<smiles>C=CC(CO)c1ccc2c(c1)OCO2</smiles>

2 'i: $77 \%$ yield<smiles>C=CC(CO)c1ccc2ccccc2c1</smiles>

2'j: $81 \%$ yield $>20: 1 ; 90 \%$ ee<smiles>C=CC(CO)c1ccc(OC)cc1</smiles>

\section{2'd: $70 \%$ yield} 9:1; $90 \%$ ee<smiles>C=CC(CO)c1ccc(C(C)(C)C)cc1</smiles>

2'e: $73 \%$ yield $>20: 1 ; 91 \%$ ee<smiles>C=CC(CO)c1ccc(C(F)(F)F)cc1</smiles>

2'f: $56 \%$ yield $>20: 1 ; 86 \%$ ee

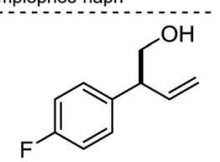

2'g: $56 \%$ yield $8: 1 ; 89 \%$ ee<smiles>C=CC(CO)c1ccc(C#C[SiH2]C)cc1</smiles>

2'o: $65 \%$ yield $>20: 1 ; 89 \%$ ee<smiles>C=CC(CO)c1cccc(OC)c1</smiles>

2'k: $73 \%$ yield $>20: 1 ; 91 \%$ ee

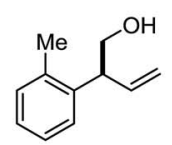

2'I: $56 \%$ yield $2.6: 1 ; 88 \%$ ee

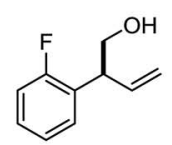

2'm: 70\% yield $15: 1 ; 87 \%$ ee<smiles>C=CC(CO)c1ccc(C#N)cc1</smiles>

2'n: $24 \%$ yield 13:1; $85 \% e e^{a}$<smiles>C=CC(CO)c1cn(C(C)(C)C)c2ccccc12</smiles>

2 'p: $28 \%$ yield 1.3:1; $86 \%$ ee<smiles>C=CC(CO)c1ccc(OC)nc1</smiles>

2'r: $45 \%$ yield $5: 1 ; 80 \% e e^{b}$<smiles>C=CC(CO)C1=CCCCC1</smiles>

2's: $88 \%$ yield $>20: 1 ; 89 \%$ ee<smiles>C=CC(/C=C/C1=C([N+](=O)[O-])CCCC1(C)C)CO</smiles>

2 't: $60 \%$ yield $>20: 1 ; 80 \%$ ee

Fig. 2 Sequential borylation/oxidation of 2-(hetero)aryl substituted 1,3-dienes. Reaction conditions: $1 \mathrm{a}(0.36 \mathrm{mmol}), \mathrm{B}_{2}(\mathrm{pin})_{2}(0.30 \mathrm{mmol})$. Chemoselectivity assessed by ${ }^{1} \mathrm{H}$ NMR after borylation. Yields of isolated alcohols $2^{\prime}$. Enantioselectivity determined after oxidation by HPLC, GC or SFC using a chiral stationary phase. ${ }^{a}$ The minor isomer is $4^{\prime} \mathrm{n} .{ }^{b}$ Isolated as a $5: 1$ mixture.

$\mathbf{2}^{\prime} \mathbf{r}$. Finally, skipped dienes 2 's-t - which derived from the parent dendralenic 1,3-dienes - were isolated as single regioisomers in good yield and high enantioselectivity.

Subsequently, conjugated 2-alkyl-1,3-dienes were investigated (Fig. 3). Counter-intuitively - perhaps - the reactivity, the chemoselectivity and the enantioselectivity were all found to increase drastically when going from primary (1u-v), to secondary $(\mathbf{1} \mathbf{w})$ and finally tertiary alkyl substituents $(\mathbf{1} \mathbf{x})$. While primary and secondary alkyl favored 4,3-borylation, a sterically

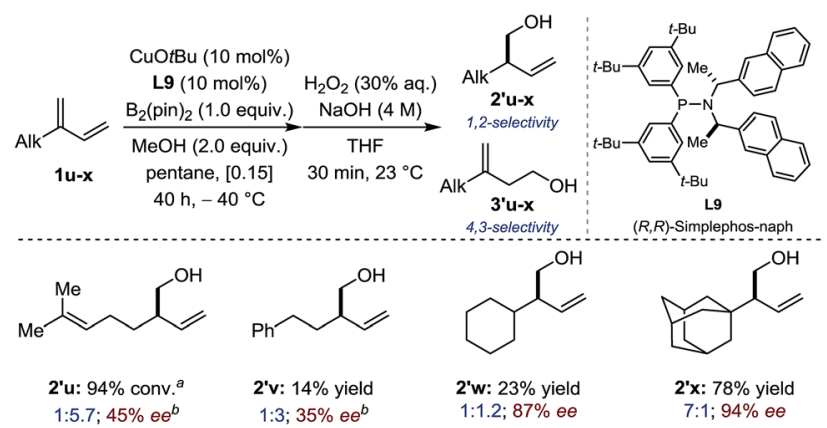

Fig. 3 Sequential borylation/oxidation of 2-alkyl substituted 1,3dienes. Reaction conditions: $1 \mathrm{u}-\mathbf{x}(0.18-0.36 \mathrm{mmol}), \mathrm{B}_{2}(\mathrm{pin})_{2}(0.15-$ $0.30 \mathrm{mmol}$ ). Chemoselectivity assessed by ${ }^{1} \mathrm{H}$ NMR after borylation. Isolated yields for alcohols $2^{\prime} \mathbf{v}-\mathbf{x}$. Enantioselectivity determined after oxidation by HPLC, GC, SFC using a chiral stationary phase. ${ }^{a}$ Conversion of non-separable isomers determined by ${ }^{1} \mathrm{H}$ NMR $\left(2^{\prime} u+3^{\prime} u\right)$. ${ }^{b}$ At $0{ }^{\circ} \mathrm{C}$ for $24 \mathrm{~h}$. demanding 1-adamantyl group restored preferential 1,2-borylation $(7: 1)$ generating $2^{\prime} \mathbf{x}$ in good yield and excellent enantioselectivity. At first sight, these data suggest that enantiodifferentiation may preferentially occur during 1,4-protodecupration from intermediate $\mathbf{C}$ rather than during 1,2-borocupration as a particularly congested quaternary $\mathrm{Cu}-\sigma$-allyl species $\mathbf{B}$ would be formed in the case of $\mathbf{2}^{\prime} \mathbf{x}$. The situation is likely to be more subtle and complex. Indeed, non-linear-effect studies revealed a substantial deviation from linearity - a signature for catalyst aggregation as is apparent from Fig. $4 .{ }^{15}$

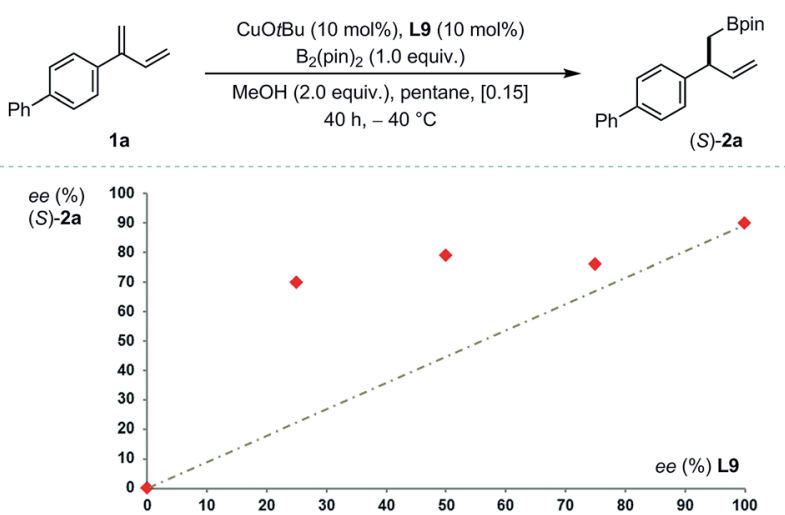

Fig. 4 Non-linear effect study. Reaction conditions: 1a $(0.12 \mathrm{mmol})$, $\mathrm{B}_{2}(\text { pin) })_{2}(0.10 \mathrm{mmol})$. Chemoselectivity $>20: 1$ in all cases as assessed by ${ }^{1} \mathrm{H}$ NMR. Enantioselectivity determined after oxidation by HPLC using a chiral stationary phase. Average of two experiments. 
Catalyst-controlled diastereoselective transformations where a chiral catalyst can install one (or several) new stereocenter(s) independently of the stereochemical complexity of the substrate have gained a certain momentum recently. ${ }^{16,17}$ Hence, the innate bias imposed by $(S)-\mathbf{1 y}$ on the Cu-catalyzed borylation was assessed using DrewPhos (L10) leading to a $2: 1$ diastereomeric ratio in favor of (S,S)-2'y (Fig. 5).$^{18}$ Diastereoselective borylation reactions were performed with both enantiomers of the chiral ligand. In the match situation $(S, S)-\mathbf{2}^{\prime} \mathbf{y}$ was isolated in $86 \%$ yield and $>20: 1 d r$ with $(R, R)$-L9. In the mismatch situation, the enantiomeric ligand $(S, S)$-L9 proved able to substantially override the substrate bias, generating $(R, S)-\mathbf{2} \mathbf{y}$ preferentially ( $85 \%$ yield; $1: 7 d r$ ). In addition to serving as a prototype for further developments, this example highlights the high chemoselectivity of our protocol as only one of the four olefinic functionalities present in $(S)$-1y underwent borylation.

Finally, double borylation of bis-diene $1 \mathrm{z}$ led preferentially to the formation of $(S, S)-\mathbf{2}^{\prime} \mathbf{z}(>99 \% e e)$ over the meso isomer $(R, S)-\mathbf{2}^{\prime} \mathbf{z}(8: 1 d r)$ (Fig. 6). This approach is based on the Horeau duplication principle and demonstrates that the catalyst can induce high levels of selectivity of each diene moiety independently of the other leading to an overall amplification. ${ }^{19,20}$

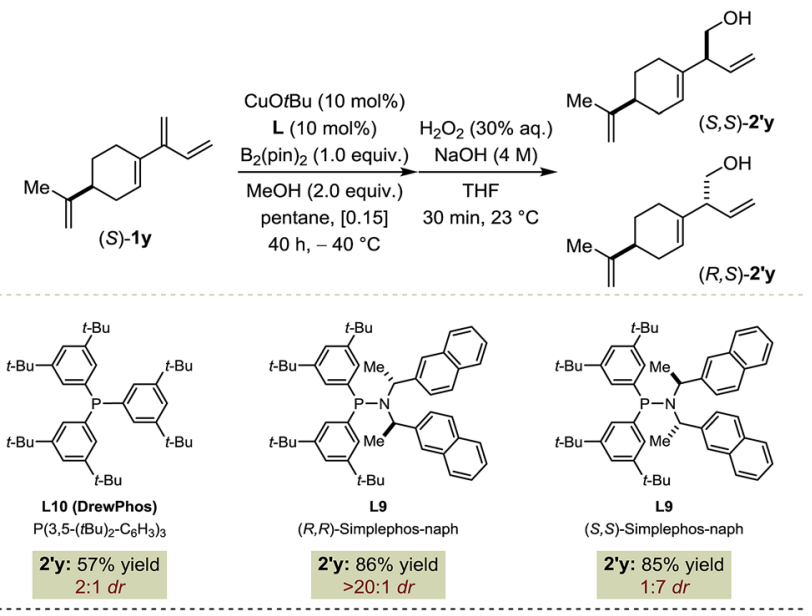

Fig. 5 Catalyst-controlled diastereoselective borylation of (S)-1y. Reaction conditions: $(S)-1 y(0.24 \mathrm{mmol}), \mathrm{B}_{2}(\text { pin })_{2}(0.20 \mathrm{mmol})$. Chemoselectivity $>20: 1$ in all cases as assessed by ${ }^{1} \mathrm{H}$ after borylation. Diastereoselectivity assessed by ${ }^{1} \mathrm{H}$ and ${ }^{13} \mathrm{C}\left\{{ }^{1} \mathrm{H}\right\}$ NMR after borylation and oxidation. Isolated yields after oxidation.
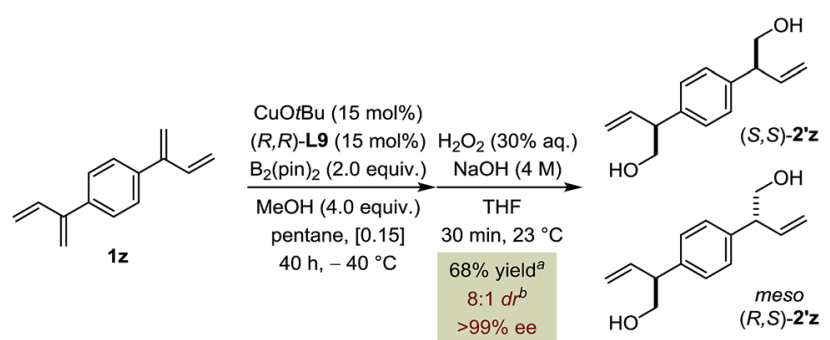

Fig. 6 Borylation/oxidation sequence of bis-diene $1 z \quad 0.36 \mathrm{mmol}$ scale). ${ }^{a} 1,2-/ 4,3-$ selectivity $=10: 1 .{ }^{b}$ Inseparable mixture.

\section{Conclusions}

In conclusion, we have developed a highly chemo-, regio- and enantioselective Cu-catalyzed borylation of 2-aryl and 2-alkyl substituted 1,3-dienes using a chiral phosphanamine ligand. The method is compatible with a broad range of functional groups and provides rapid access to synthetically relevant homoallylic boronates/alcohols and is amenable to a catalystcontrolled diastereoselective process. Further mechanistic investigations into the origin of the selectivity of this catalytic reaction are underway.

\section{Conflicts of interest}

There are no conflicts to declare.

\section{Acknowledgements}

This work was supported by the University of Geneva. S. Rosset is acknowledged for technical assistance.

\section{Notes and references}

1 (a) K. C. Nicolaou, S. A. Snyder, T. Montagnon and G. Vassilikogiannakis, Angew. Chem., Int. Ed., 2002, 41, 1668; (b) E.-I. Negishi, Z. Huang, G. Wang, S. Mohan, C. Wang and H. Hattori, Acc. Chem. Res., 2008, 41, 1474.

2 (a) H. Leicht, I. Göttker-Schnetmann and S. Mecking, ACS Macro Lett., 2016, 5, 777; (b) C. Yao, N. Liu, S. Long, C. Wu and D. Cui, Polym. Chem., 2016, 7, 1264; (c) H. Leicht, I. Göttker-Schnetmann and S. Mecking, J. Am. Chem. Soc., 2017, 139, 6823.

3 (a) J. Mahatthananchai, A. M. Dumas and J. W. Bode, Angew. Chem., Int. Ed., 2012, 51, 10954; (b) Y. Xiong, Y. Sun and G. Zhang, Tetrahedron Lett., 2018, 59, 347.

4 (a) R. J. Ely and J. P. Morken, J. Am. Chem. Soc., 2010, 132, 2534; (b) R. K. Sharma and T. V. RajanBabu, J. Am. Chem. Soc., 2010, 132, 3295; (c) A. L. Watkins and C. R. Landis, Org. Lett., 2011, 13, 164; (d) J. R. Zbieg, E. Yamaguchi, E. L. McInturff and M. J. Krische, Science, 2012, 336, 324; (e) L. T. Kliman, S. N. Mlynarski, G. E. Ferris and J. P. Morken, Angew. Chem., Int. Ed., 2012, 51, 521; (f) M. J. Goldfogel, C. C. Roberts and S. J. Meek, J. Am. Chem. Soc., 2014, 136, 6227; (g) T. Y. Chen, R. Tsutsumi, T. P. Montgomery, I. Volchkov and M. J. Krische, J. Am. Chem. Soc., 2015, 137, 1798; (h) V. Saini, M. O'Dair and M. S. Sigman, J. Am. Chem. Soc., 2015, 137, 608; (i) X. Wu, H.-C. Lin, M.-L. Li, L.-L. Li, Z.-Y. Han and L.-Z. Gong, J. Am. Chem. Soc., 2015, 137, 13476; (j) Y. Liu, Y. Xie, H. Wang and H. Huang, J. Am. Chem. Soc., 2016, 138, 4314; $(k)$ S. E. Korkis, D. J. Burns and H. W. Lam, J. Am. Chem. Soc., 2016, 138, 12252; (l) X.-H. Yang and V. M. Dong, J. Am. Chem. Soc., 2017, 139, 1774; $(m)$ N. J. Adamson, E. Hull and S. Malcolmson, J. Am. Chem. Soc., 2017, 139, 7180; (n) Y.-Y. Gui, N. Hu, X.-W. Chen, L.-L. Liao, T. Ju, J.-H. Ye, Z. Zhang, J. Li and D.-G. Yu, J. Am. Chem. Soc., 2017, 139, 17011. 
5 (a) T. Smejkal, H. Han, B. Breit and M. J. Krische, J. Am. Chem. Soc., 2009, 131, 10366; (b) Y. Ebe and T. Nishimura, J. Am. Chem. Soc., 2014, 136, 9284; (c) Q.-A. Chen, D. K. Kim and V. M. Dong, J. Am. Chem. Soc., 2014, 136, 3772; (d) M. S. McCammant and M. S. Sigman, Chem. Sci., 2015, 6, 1355; (e) K. D. Nguyen, D. Herkommer and M. J. Krische, J. Am. Chem. Soc., 2016, 138, 14210; (f) S. Oda, J. Franke and M. J. Krische, Chem. Sci., 2016, 7, 136; $(g)$ L. Jiang, P. Cao, M. Wang, B. Chen, B. Wang and J. Liao, Angew. Chem., Int. Ed., 2016, 55, 1385; $(h)$ X. Li, F. Meng, S. Torker, Y. Shi and A. H. Hoveyda, Angew. Chem., Int. Ed., 2016, 55, 9997; (i) X.-H. Yang, A. Lu and V. M. Dong, J. Am. Chem. Soc., 2017, 139, 14049.

6 (a) H. Li, D. Fiorito and C. Mazet, ACS Catal., 2017, 7, 1554; (b) D. Fiorito, S. Folliet, Y. Liu and C. Mazet, ACS Catal., 2018, 8, 1392.

7 (a) M. Satoh, Y. Nomoto, N. Miyaura and A. Suzuki, Tetrahedron Lett., 1989, 30, 3789; (b) J. Y. Wu, B. Moreau and T. Ritter, J. Am. Chem. Soc., 2009, 131, 12915.

8 (a) Y. Sasaki, C. Zhong, M. Sawamura and H. Ito, J. Am. Chem. Soc., 2010, 132, 1226; (b) J. V. Obligacion and P. J. Chirik, J. Am. Chem. Soc., 2013, 135, 19107; (c) A. D. Ibrahim, S. W. Entsminger and A. R. Fout, ACS Catal., 2017, 7, 3730.

9 (a) K. Semba and Y. Nakao, J. Am. Chem. Soc., 2014, 136, 7567;

(b) K. B. Smith, K. M. Logan, W. You and M. K. Brown, Chem.-Eur. J., 2014, 20, 12032; (c) K. M. Logan, K. B. Smith and M. K. Brown, Angew. Chem., Int. Ed., 2015, 54, 5228; (d) T. Jia, P. Cao, B. Wang, Y. Lou, X. Yin, M. Wang and J. Liao, J. Am. Chem. Soc., 2015, 137, 13760; (e) K. M. Logan and M. K. Brown, Angew. Chem., Int. Ed., 2017, 56, 851; (f) B. Chen, P. Cao, X. Yin, Y. Liao, L. Jiang, J. Ye, M. Wang and J. Liao, ACS Catal., 2017, 7, 2425.

10 (a) K. B. Smith and M. K. Brown, J. Am. Chem. Soc., 2017, 139, 7721; (b) S. R. Sardini and M. K. Brown, J. Am. Chem. Soc., 2017, 139, 9823.

11 (a) T. Miura, Y. Takahashi and M. Murakami, Chem. Commun., 2007, 595; (b) B. Yu, F. Menard, N. Isono and M. Lautens, Synthesis, 2009, 853; (c) J. Kim, S. Park, J. Park and S. H. Cho, Angew. Chem., Int. Ed., 2016, 55, 1498; (d) V. J. Garza and M. J. Krische, J. Am. Chem. Soc., 2016, 138, 3655; (e) Y. Shi and A. H. Hoveyda, Angew. Chem., Int. Ed., 2016, 55, 3455; $(f)$ M. Zhan, R.-Z. Li, Z.-D. Mou, C.-G. Cao, J. Liu, Y.-W. Chen and D. Niu, ACS Catal., 2016, 6, 3381.

12 (a) K. Semba, T. Fujihara, J. Terao and Y. Tsuji, Tetrahedron, 2015, 71, 2183; (b) E. C. Neeve, S. J. Geier, I. A. I. Mkhalid, S. A. Westcott and T. B. Marder, Chem. Rev., 2016, 116, 9091; (c) C. Diner and K. J. Szabó, J. Am. Chem. Soc., 2017, 139, 2.

13 (a) J.-E. Lee and J. Yun, Angew. Chem., Int. Ed., 2008, 47, 145; (b) Y. Lee and A. H. Hoveyda, J. Am. Chem. Soc., 2009, 131, 3160; (c) Y. Lee, H. Jang and A. H. Hoveyda, J. Am. Chem.
Soc., 2009, 131, 18234; (d) J. C. H. Lee, R. McDonald and D. G. Hall, Nat. Chem., 2011, 3, 894; (e) R. Corberán, N. W. Mszar and A. H. Hoveyda, Angew. Chem., Int. Ed., 2011, 50, 7079; (f) Y. Sasaki, Y. Horita, C. Zhong, M. Sawamura and H. Ito, Angew. Chem., Int. Ed., 2011, 50, 2778; $(g)$ K. Semba, M. Shinomiya, T. Fujihara, J. Terao and Y. Tsuji, Chem.-Eur. J., 2013, 19, 7125; (h) K. Kubota, K. Hayama, H. Iwamoto and H. Ito, Angew. Chem., Int. Ed., 2015, 54, 8809; (i) C. Jarava-Barrera, A. Parra, A. López, F. Cruz-Acosta, D. Collado-Sanz, D. J. Cárdenas and M. Tortosa, ACS Catal., 2016, 6, 442; (j) K. Kubota, Y. Watanabe, K. Hayama and H. Ito, J. Am. Chem. Soc., 2016, 138, 4338; ( $k$ ) Z. Wang, X. He, R. Zhang, G. Zhang, G. Xu, Q. Zhang, T. Xiong and Q. Zhang, Org. Lett., 2017, 19, 3067.

14 (a) L. Palais, I. S. Mikhel, C. Bournaud, L. Micouin, C. A. Falciola, M. V. Augustin, S. Rosset, G. Bernardinelli and A. Alexakis, Angew. Chem., Int. Ed., 2007, 46, 7462; (b) C. Hawner, K. Li, V. Cirriez and A. Alexakis, Angew. Chem., Int. Ed., 2008, 47, 8211; (c) L. Palais and A. Alexakis, Chem.-Eur. J., 2009, 15, 10473; (d) L. Palais, C. Bournaud, L. Micouin and A. Alexakis, Chem.-Eur. J., 2010, 16, 2567; (e) D. Müller and A. Alexakis, Org. Lett., 2012, 14, 1842; (f) D. Müller, L. Guénée and A. Alexakis, Eur. J. Org. Chem., 2013, 6335; $(g)$ H. Li, D. Grassi, L. Guénée, T. Bürgi and A. Alexakis, Chem.-Eur. J., 2014, 20, 16694.

15 (a) H. B. Kagan, in Comprehensive Asymmetric Catalysis, ed. E. N. Jacobsen, A. Pfaltz and H. Yamamoto, Springer, Berlin, 1999, ch. 4; (b) D. G. Blackmond, Acc. Chem. Res., 2000, 33, 402; (c) T. Satyanarayana, S. Abraham and H. B. Kagan, Angew. Chem., Int. Ed., 2009, 48, 456.

16 (a) Comprehensive Asymmetric Catalysis, ed. E. N. Jacobsen, A. Pfaltz, and H. Yamamoto, Springer, Berlin, 1999; (b) Fundamentals of Asymmetric Catalysis, ed. P. J. Walsh and M. C. Kozlowski, University Science Books, Sausalito, CA, 2009.

17 (a) A. Hassan, Y. Lu and M. J. Krische, Org. Lett., 2009, 11, 3112; (b) I. Shin, G. Wang and M. J. Krische, Chem.-Eur. J., 2014, 20, 13382; (c) H. Li and C. Mazet, J. Am. Chem. Soc., 2015, 137, 10720.

18 (a) A. P. Cinderella, B. Vulovic and D. A. Watson, J. Am. Chem. Soc., 2017, 139, 7741; (b) B. Vulovic, A. P. Cinderella and D. A. Watson, ACS Catal., 2017, 7, 8113.

19 (a) J.-P. Vigneron, M. Dhaenes and A. Horeau, Tetrahedron, 1973, 29, 1055; (b) S. Baba, K. Sartor and H. B. Kagan, Bull. Soc. Chim. Fr., 1994, 131, 525; (c) F. Lagasse, M. Tsukamoto and H. B. Kagan, J. Am. Chem. Soc., 2003, 125, 7490.

20 When 1,3-dienes with other substitutions patterns (2,3-disubstituted, linear, cyclic...) were investigated with our optimized conditions, unsatisfactory levels of selectivity were observed. See ESI. $\dagger$ 